\title{
Teaching on natural risks by simulation in Minetest and augmented reality
}

\author{
Lecordix François ${ }^{a}$ *, Kumarasamy Sivakavi a \\ ${ }^{a}$ Institut national de l'information géographique et forestière,France,francois.lecordix@ign.fr, sivakavi.kumarasamy@ign.fr \\ * Corresponding author
}

Keywords: Education, Simulation, Augmented reality, Flood

\begin{abstract}
:
To offer new innovative digital services, the French Ministry of Education funded the IGN, from March 2018 to March 2020, to carry out OPIUM Project: Innovative teaching tools in Minetest universe. This project led to the new geographic application "Minetest digital game" in the service Edugéo, dedicated to teachers and students. Offered by IGN, Edugéo already offers 3 modules to help teach geography in the school curriculum. The 4th module introduced makes it possible to approach geography with the sandbox type game Minetest (free version of Minecraft) by introducing natural risk simulation tools (flood, avalanche, volcanic eruption, mudslide, tornado) in the game, applicable at any point of the national territory with geographic data from IGN and worldwide with data from OSM.
\end{abstract}

The "Minetest digital game" module is made up of two parts:

- Minetest on demand service which makes it possible to order a Minetest map, with a footprint of up to $5 \mathrm{~km}$ by $5 \mathrm{~km}$, made with geographic data. Minetest on Demand added many options of the service Minecraft on demand that we presented at ICC 2017 at Washington and ICC 2019 at Tokyo.

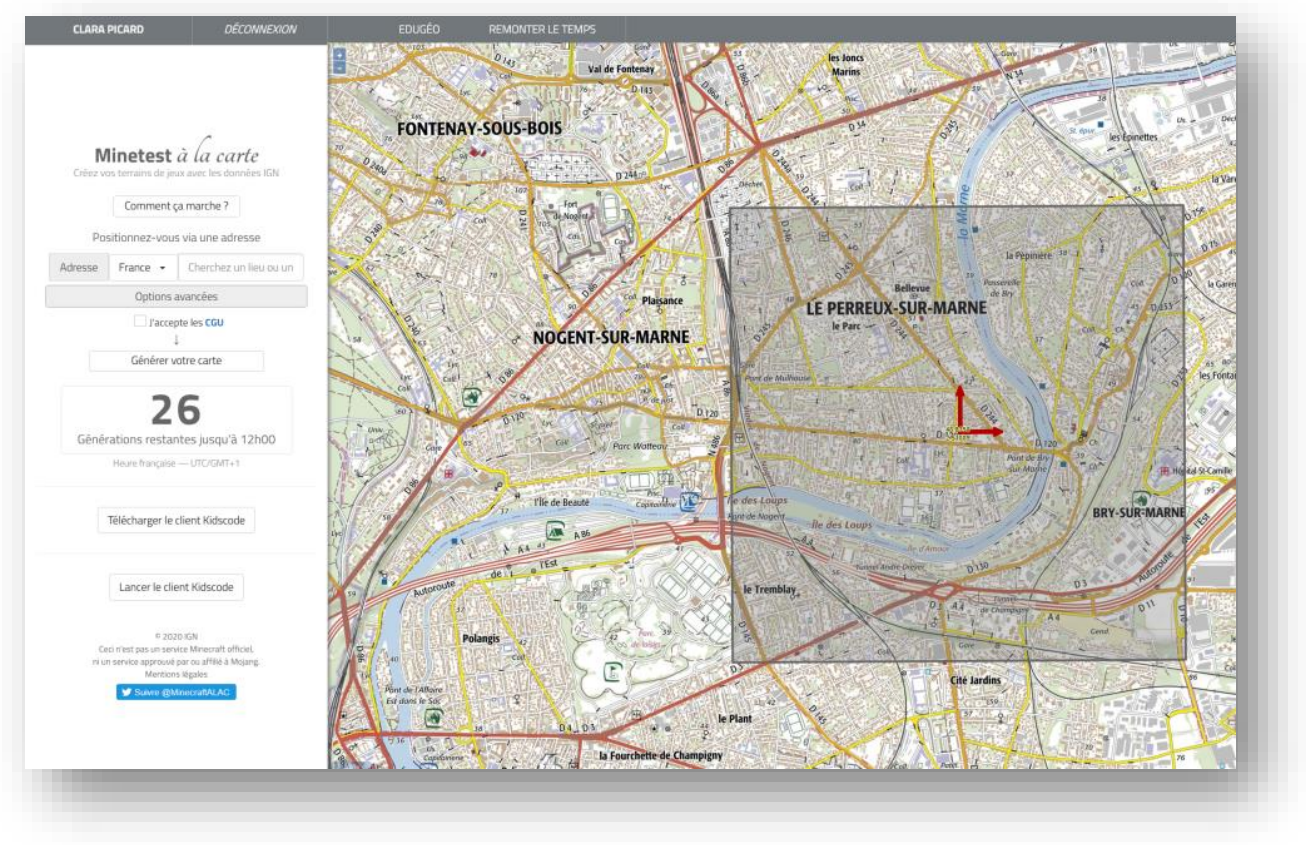

Figure 1. Interface Minetest on demand to order Minetest map with geographic data

- The downloadable Minetest / Kidscode platform which will allow teaching with this map, in particular by making it possible to simulate natural risks. Examples will be detailed in the article, in particular on the last floods that occurred in France in February 2021 on the river Garonne, with simulation results very close to the results observed in the field with orthophotos made by the IGN during the crisis, especially in the village of Couthures sur Garonne. 


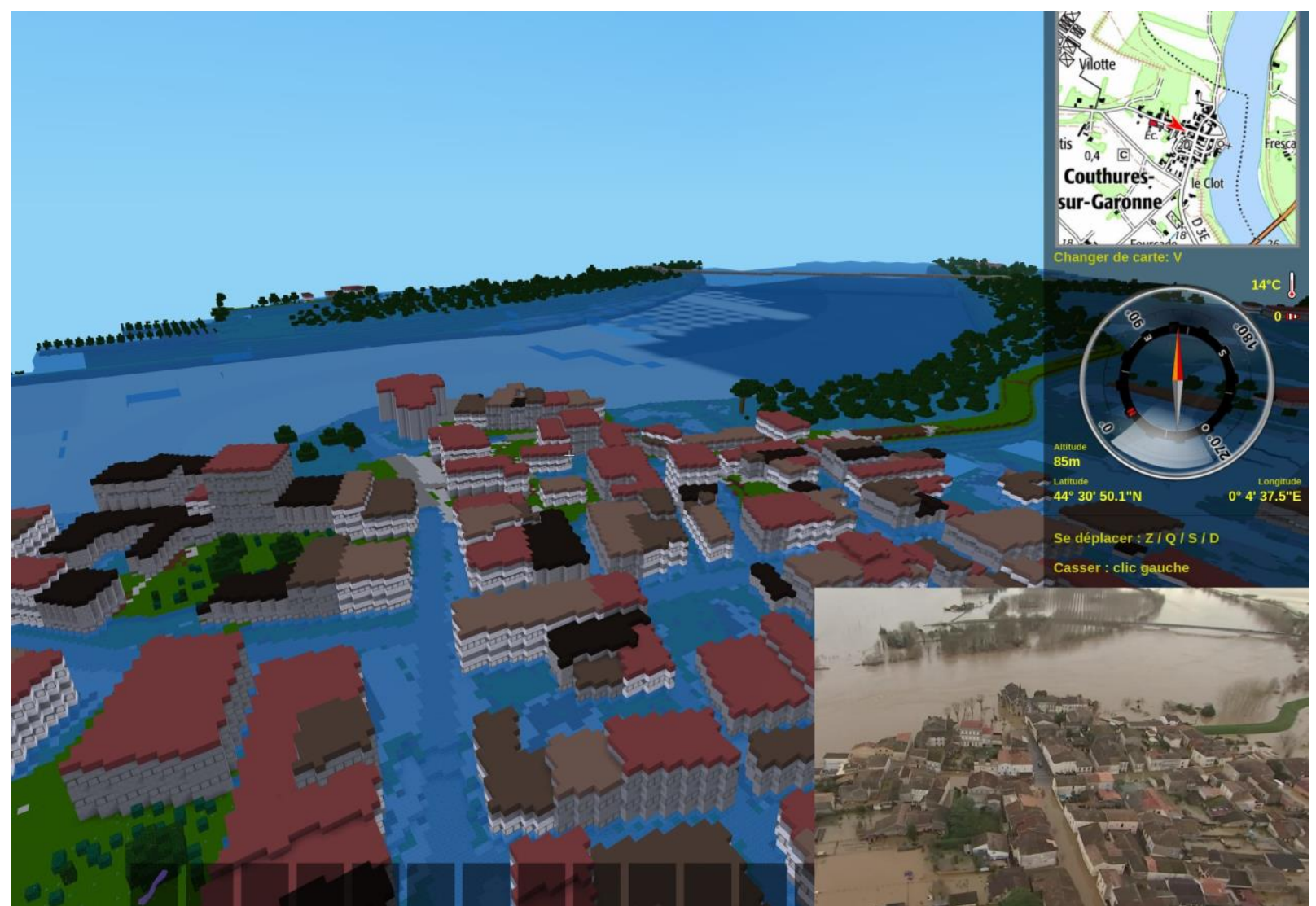

Figure 2. 3D simulation in Minetest / Kidscode of the flood at Couthures sur Garonne in February 2021 and aerial photo of the flood

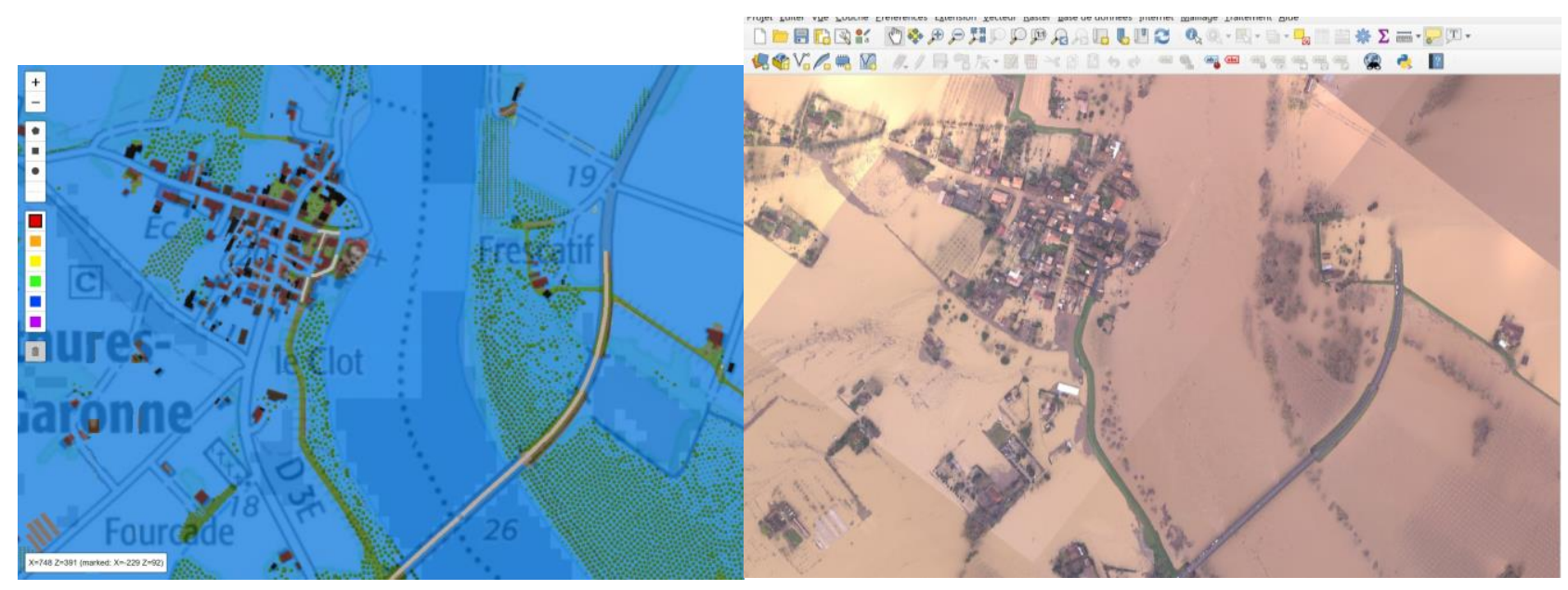

Figure 3. 2D simulation in Minetest / Kidscode of the flood at Couthures sur Garonne in February 2021 and orthophoto photo of the flood

In order to facilitate the referencing of the solution in textbooks, IGN continued work in 2021 to add an augmented reality solution making it possible to visualize the results of simulations obtained in Minetest directly on a tablet from a simple printout. in 2D. The techniques implemented to set up this augmented reality solution will be presented. 


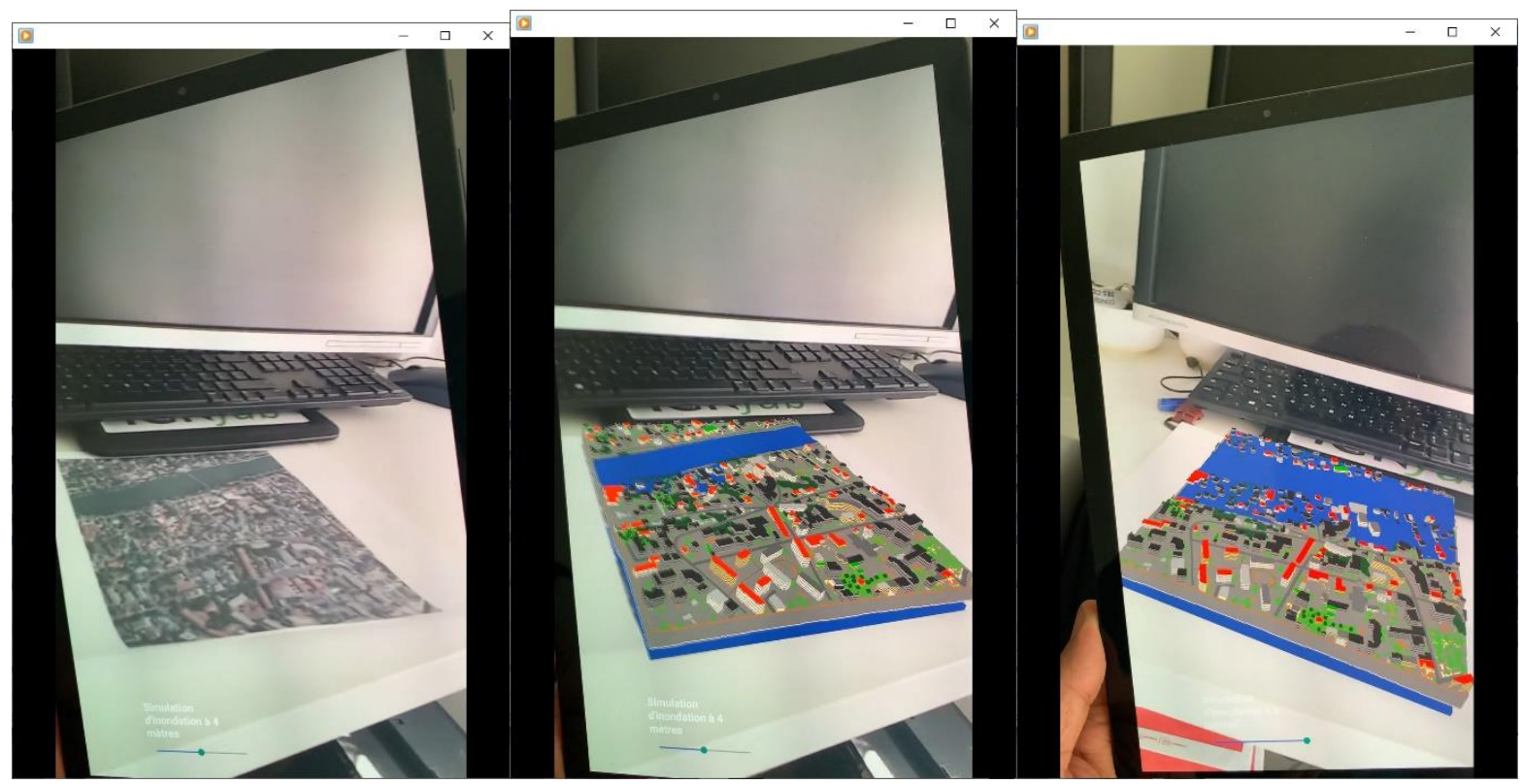

Figure 4. Augmented reality experiment for flood simulation in Minetest/Kidscode 